\title{
Quality characteristics of clean rice with the processing system
}

\author{
Oui-Woung Kim, Hoon Kim, Hyo-Jai Lee, Jae Hwan Ahn* \\ Research Group of Smart Food Distribution System, Korea Food Research Institute, Seongnam 13539, Korea
}

\section{클린라이스 제조방식에 따른 백미의 품질 특성}

\author{
김의웅·김훈·이효재·안재환* \\ 한국식품연구원 스마트유통시스템연구단
}

\begin{abstract}
Clean rice is useful to save time and labor force against washing rice in the household. Nevertheless the quality characteristics of the rice were not established well since the quality characteristics of the rice depend on types of the processing system. The aims of the current study were to understand the quality characteristics of clean rice prepared from the dry, semi-dry, and wet types of processing systems, and to suggest the appropriate processing system for production of clean rice. Here, we found that the quality of clean rice was improved with the increasing whiteness of rice by the dry type, although the whiteness of rice should be below 42 to satisfy 16.0 NTU of the turbidity for higher head rice ratio. Also, both the semi-dry and wet type systems showed higher ratio of head rice than the dry type system at below $16.0 \mathrm{NTU}$ of the turbidity. These results imply that the wet type is more suitable for the place where rice is consumed fast, and the semi-dry type is more proper for long term storage of rice.
\end{abstract}

Key words : clean rice, processing method, quality characteristics, milled rice

\section{서 론}

백미는 물에 씻어 표면의 잔류 미강을 제거한 후 취반을 하는 것이 일반적이다. 그러나 이렇게 물에 씻는 경우, 잔류 미강이 하천으로 흘러 들어가면서 환경오염의 원인이 될 뿐만 아니라, 대량으로 밥을 짓는 경우 잔류 미강 제거를 위해 많은 시간과 노동력을 필요로 한다. 이러한 부분을 해결하기 위해 백미의 표면을 연마하거나 세척하여 잔류 미강을 제거함으로써, 씻지 않고 바로 취반이 가능한 클린 라이스가 제시되었다(1). 클린라이스는 제조방식에 따라 도정도를 조정하여 백미의 호분층 및 잔류 미강을 제거하는 건식, 공기에 가습을 하여 고습도 조건에서 호분층 및 잔류 미강을 제거하는 반건식, 도정 후 수세와 건조를 하여 제조

*Corresponding author. E-mail : jhahn@kfri.re.kr

Phone : 82-2-780-9426, Fax : 82-2-780-9059

Received 3 May 2016; Revised 25 May 2016; Accepted 3 June 2016.

Copyright (c) The Korean Society of Food Preservation. All rights reserved.
하는 가수정미방식, 그리고 타피오카전분이나 미강을 활용 한 특수방식의 4 가지로 구분할 수 있다(2).

클린라이스는 제조방식에 따라 품질 특성이 다르며(3), 제거되는 잔류 미강의 양이나 도정특성에 따라 차이가 날 수 있다. 클린라이스 제조방식에 대한 연구는 주로 가수정 미방식 시스템에 대해 행해졌는데, Jang 등(4)은 가수정미 방식을 이용한 대규모 클린라이스 생산·가공 공정 시스템 개발을 위해서 가공용량, 세미시간, 함수율 등의 설계기준 에 대해 연구하였다. Choi 등(5)은 기존의 가수정미방식에 정전기 이용 제거 방식을 추가하여 일반 가수정미방식 시스 템보다 물을 적게 쓰는 클린라이스 제조 시스템을 제시하였 다. 또한, 가수정미방식에서는 쌀을 수세와 건조를 할 경우 미립의 빛이 산란되어 반사가 증가하고, 빛의 투과가 감소 하는 백화현상이 발생하여 외관품질이 저하되고(6), 낟알 내부와 표면의 수분차에 의한 응력으로 인한 표면균열 발생 (7) 등의 문제가 발생한다고 연구되었다. 또한 건식 방식에 대해서는 $\operatorname{Kim}$ 등(8)이 잔류 미강의 제거 정도와 식미특성 을 고려하여 고품질쌀 생산을 하면서도 일정한 도정수율을 유지할 수 있는 백도 조건을 제시하였으며, 반건식 방식이 
이용하는 습식 연미기에 대해 습식 연미기 관련 연구가 수행되어 왔다(9-11). 한편, 제조방식에 따라 클린라이스의 저장특성이 달라질 수 있기 때문에 Kim 등(12)은 건식, 반건 식, 가수정미방식에 대해 저장기간 및 저장온도를 변화시 키며 고찰하였다.

클린라이스의 각 제조방식의 특징에 따라 품질 차이가 날 수 있으나 품질 특성에 대한 연구결과는 없으며, 제조방 식에 따른 클린라이스 관련 품질 특성의 정확한 자료 및 비교 분석이 없이 클린라이스가 제조되고 있어 생산자와 소비자들이 제조방식에 따른 정확한 정보를 얻기가 어려운 상황이다. 이를 위해 본 연구에서는 현재 상용화되어 있는 클린라이스 제조기술 중 건식, 반건식, 가수정미방식에 대 해 품질 특성을 제시 및 비교하고자 한다. 이를 위해 건식 제조방식에서 백도에 따른 $\mathrm{CBB}$ 인덱스, 탁도, 건고물량을 측정하여 기본적인 클린라이스 품질 특성을 고찰하고자 한다. 또한, 건식, 반건식, 가수정미방식에 따라 곡온, 함수 율, 싸라기 발생율, 완전미수율 등의 품질 특성을 비교 분석 하여 적합한 제조방식을 제시하고자 한다.

\section{재료 및 방법}

\section{실험재료 및 실험장치}

건식 방식의 클린라이스 제조시스템에서 도정도에 따른 과피, 호분층, 배유층 등의 상태를 확인하기 위해 백도가 23.2에서 48.5까지 되도록 시험용 마찰식정미기(VP-31T, Yamamoto, Higashine-shi, Japan)를 사용하여 건식 시료를 제조하였다. 또한 각 제조시스템을 비교하기 위해 백미의 백도가 $39,40,41,42$ 수준이 되도록, 건식과 반건식 시료를 제조하였으며, 가수정미방식의 시료는 건식에서 제조된 백 도 $39,40,41,42$ 의 4 가지 시료를 원료로 사용하여 가수정미 방식 시료를 제조하였고, 그에 따라 총 제조된 시료는 12 가 지였다. 시료제조 중 외기의 평균 온도 및 습도는 각각 7. $8^{\circ} \mathrm{C}, 12.0 \% \mathrm{RH}$, 가공실 내부의 평균 온도 및 습도는 각각 $12.3^{\circ} \mathrm{C}, 9.0 \% \mathrm{RH}$ 이었다. 제조된 시료는 $5^{\circ} \mathrm{C}$ 를 유지하는 저 온저장고에 보관하면서 실험 12 시간 전에 실온에 방치한 후 품질측정에 공시하였다.

실험에 사용한 건식 정미시스템(Kapika, Yamamoto, Higashine-shi, Japan)은 2마찰 1건식연미 방식으로 $2 \mathrm{ton} / \mathrm{hr}$ 의 처리능력을 가진 one pass형 정미시스템이었으며, 작동 전류가 각각 21-115-25A수준이었다. 반건식 정미시스템 (NCP, Satake Co., Hiroshima, Japan)은 1연삭 1마찰 1습식연 미 방식이며 $5 \mathrm{ton} / \mathrm{hr}$ 의 처리능력을 가지고 있고, 습식연미 가수량은 $0.3 \mathrm{~L} / \mathrm{min}$, 각 단의 작동전류는 90-165-125A수준 이었다. 한편, 가수정미방식에서는 처리능력 $1.2 \mathrm{ton} / \mathrm{hr}$ 의 시스템(SJR, Satake Co., Hiroshima, Japan)을 이용하여 건식 에서 제조된 시료를 3 번 가수 $(4.7,0.97,1.23 \mathrm{~L} / \mathrm{min})$ 하여
총 $6.94 \mathrm{~L} / \mathrm{min}$ 를 가수하여 제조하였으며, 작동전류는 20-115-25-56A수준이었다.

\section{품질 특성 측정}

함수율은 $10 \mathrm{~g}$ 의 곡립을 오븐에서 $135^{\circ} \mathrm{C}$ 로 24 시간 동안 건조하여 건조 전후의 무게차를 이용하여 측정한 후 $5 \mathrm{~g}$ 분쇄 $-105^{\circ} \mathrm{C}-5$ 시간 표준 측정법으로 환산하여 이용하였다. 환산식은 식 아래와 같으며, $\mathrm{M}_{105}$ 는 $105^{\circ} \mathrm{C}$ 법에 의한 함수율 (\%, wet bulb(w.b.)), $\mathrm{M}_{135}$ 는 $135^{\circ} \mathrm{C}$ 법에 의한 함수율 (\%,w.b.) 를 의미한다(13).

$$
\mathrm{M}_{105}=100-1.0121\left(100-\mathrm{M}_{135}\right)
$$

백도는 백도계(CR 300-3, Kett, Tokyo, Japan)를 이용하여 동일시료를 5 회 반복 측정하였고, 최대값과 최소값을 제외 한 3회 측정치의 평균값을 사용하였다. 곡물온도는 곡온계 (Testo 75-R, Testo, Sparta Township, NJ, USA)를 사용하였 다. 도정도는 정립 1,000 립의 중량인 천립중을 이용하여 측정(8)하였으며, 싸라기함량은 정립 낟알의 평균길이의 $3 / 4$ 미만인 낟알을 수작업으로 측정하였다. 완전미수율 (Head rice ratio)는 식은 아래와 같이 계산하였으며, 투입된 현미 무게 대비 백미 중 완전미 무게를 나타낸다.

$$
\begin{aligned}
& \text { Headrice ratio }(\%)=(100-\text { Deree of milling }(\%)) \\
& \times(100-\text { Broken ke rnels ratio }(\%))
\end{aligned}
$$

$\mathrm{CBB}$ (Colored bran balance) index는 Yoon 등(14)이 사용 한 개념을 적용하여 설계·제작한 측정장치(SE-01, Sensor Eye Co., Daejeon)를 이용하였고, 백미 정상립 50 립의 평균 치를 사용하였다. 과피는 진한 녹색, 호분층은 진한 청색, 그리고 전분층은 노란색의 가상의 색으로 구분하여 면적을 산출하고 과피와 호분층의 면적비율을 구하여 식 아래와 같이 $\mathrm{CBB}$ index를 계산하였다. 계산된 $\mathrm{CBB}$ index를 기준으 로 최대값과 최소값의 차이를 도정편차 즉, 잔류 미강의 차이로 하였다.

$$
\begin{aligned}
& C B B \text { inde } x= \\
& \frac{\text { pericarp layer }+ \text { aleurone layer }}{\text { pericarp layer }+ \text { aleurone layer }+ \text { endosperm layer }} \times 100
\end{aligned}
$$

표면 SEM(Scanning Electron Microscope) 특성을 확인하 기 위해 sputter coater(Spi supplies, West chester, PA, USA) 를 이용하여 10 30 nm의 두께로 gold-palladium으로 도금 한 후, 도금된 시료를 주사전자현미경(Scanning electron micrographs, SEM, S2380N, Hitachi, Tokyo, Japan)을 이용 하여 가속전압 $20 \mathrm{kV}$ 에서 1,000 배율로 촬영하였다.

탁도 측정을 위한 현탁액 제조는 일본정미공업회 기준을 참고하여 실시하였다. 시료 $5 \mathrm{~g}$ 을 $1,000 \mathrm{~mL}$ 삼각플라스크 
에 투입한 후, $20^{\circ} \mathrm{C}$ 의 증류수 $400 \mathrm{~mL}$ 를 가하여, 진탕기 (SR-25, TAITEC, Koshigaya-shi, Japan)에 장착한 후, 진동 의 진폭 $40 \mathrm{~mm}$, 진동수 150 회/분, 진동시간 30 초로 설정된 진탕기로 진탕하여 현탁액을 채취하였다. 탁도측정은 NTU 단위를 측정할 수 있는 탁도계(2100N Turbidimeter, Loveland, CO, USA)로 3 회 반복 측정하여 평균치를 사용하 였다(15). 건고물량은 이물, 싸라기, 분상질립 등을 제거한 시료 $20 \mathrm{~g}$ 을 3점으로 균분한 후, $15^{\circ} \mathrm{C}$ 의 증류수 $300 \mathrm{~mL}$ 를 가수하여 100 회/400초의 속도로 진탕하고 상등액을 $10 \mathrm{~mL}$ 채취하여 측정하였다. 채취한 액은 $105^{\circ} \mathrm{C}$ 에서 건조하여 방 냉한 후 측정한 중량의 평균치를 이용하였다(6).

\section{결과 및 고찰}

\section{건식 방식의 도정조건에 따른 클린라이스 품질 특성}

건식 방식에서는 겉부분의 호분층을 완전히 제거함에 의해 표면의 잔류 미강을 최소화하므로 호분층을 어느정도 수준으로 제거할 것인지에 대한 도정도가 매우 중요하다. 도정도가 낮을 경우 잔류 미강이 남아 있을 수 있고, 도정도 가 높을 경우 과도한 도정으로 인해 중량이 감소하여 수율 이 낮아지기 때문에, 적정한 수준의 도정도를 결정하여야 한다.

백도는 백미 품질의 기준이 되는 중요한 수치 중 하나로 서, 완전한 어둠을 0 으로 하고, $\mathrm{Mg}$ 리본을 태웠을 때 발생하 는 하얀색 연기를 100 으로 하여 그 사이를 100 등분한 빛의 반사지수이다. 여러 색인자 중 백도가 도정도를 가장 잘 나타낼 수 있으며, 백도 40 이상에서 식미가 높게 나타나 고품질 쌀의 도정도는 백도 40 41(도정도 8.9 9.2\%)에서 적정한 것으로 나타났다(8). Fig. 1은 0.0 15.3\% 범위의 도 정도에 따른 백도 변화를 나타냈다. 도정도가 증가함에 따 라 백도는 증가하는 경향을 나타내었나, 도정도 $12 \%$ 이상

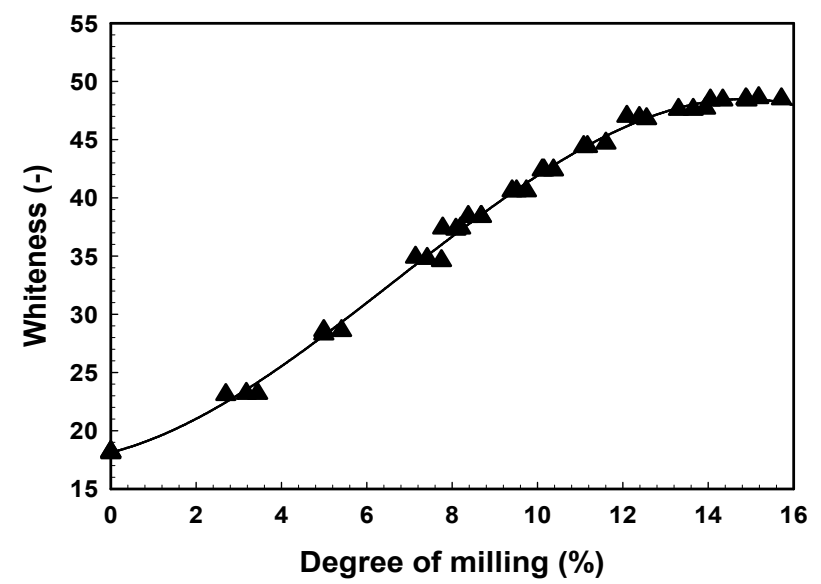

Fig. 1. Variation of whiteness with degree of milling in the dry type of the processing system.
에서는 도정도 증가에 따른 백도의 증가율이 급격히 감소하 였다. 도정도 $15.3 \%$ 에서 백도값은 48.5 로 최대를 나타내었 으며, 일정 도정도 이상에서는 호분층이 완전히 제거됨에 따라 백도가 더 이상 증가하지 않았다. 도정 중에 중량을 측정하는 것이 어렵기 때문에, 현장에서는 도정도 위주의 도정기준보다는 백도 위주의 도정기준이 활용되고 있다.

Table 1은 백도 변화에 따른 낟알의 이미지와 CBB index 를 나타낸다. CBB index는 전 면적 대비 호분층이 남아있는 부분의 면적비로 정의되며, 도정도 및 백도와 밀접한 관계 를 나타낸다(14). 백도가 증가하면서 과피인 녹색과, 호분 층의 청색의 면적이 감소하였다. 고품질쌀의 도정기준인 백도 40(8)과 가까운 40.6에서 골부분에 약간의 미강이 남 아있어, 평균 $\mathrm{CBB}$ index는 약 0.8 정도를 나타내었다. 도정 이 많이 진행된 백도 46.9 부터 48.4 까지는 평균 CBB index 값이 0.1 로 차이가 없었으며, 최종 백도 48.5 에서는 $\mathrm{CBB}$ index가 0.0 수준이었다. 그러나 부적절한 도정배분이나 배 아 부착율 등에 따라 발생되는 낟알간의 CBB index차이인 도정편차는 백도 40.6 일 때 1.3 , 백도 44.5 일 때 0.6 , 백도 48.5 일 때 0.2 로 나타났으며, 백도가 증가함에 따라 도정편 차가 감소하여 균일한 크기의 낟알을 얻을 수 있으나 중량 감소로 인해 수율은 감소하게 된다.

Fig. 2는 백도 변화에 따른 탁도(a)와 건고물량(b)을 나타 낸다. 클린라이스의 탁도 기준으로 일본에서는 $28 \mathrm{ppm}$ 과 $40 \mathrm{ppm}$ 을 사용하고 있으나, 통일된 기준이 없어서 두 가지 모두를 사용하고 있다. 국내에서는 탁도 기준이 전무한 실 정이며, $\mathrm{Kim}$ 등(16)이 품질기준안으로 제시한 16.0 $\mathrm{NTU}(34.5 \mathrm{ppm})$ 가 유일하다. Fig. 2a에서 백도가 증가함에 따라 탁도는 증가하다가 감소하였으며, 백도 34.8에서 탁도 는 $39.0 \mathrm{NTU}$ 로 최대치를 나타냈다. 도정이 진행됨에 따라 과피가 제거되고 호분층이 노출되는데, 호분층은 세포벽의 형상이 일정하지 않아 최대로 많은 호분층 세포벽이 파괴되 어 있을 때 최대 탁도를 나타내다가, 호분층이 점차 제거되
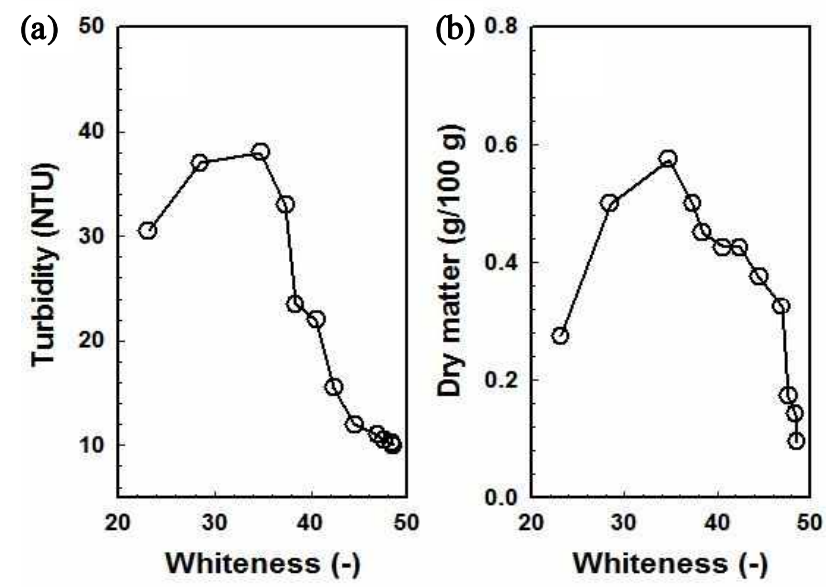

Fig. 2. Variations of turbidity (a) and dry matter (b) with whiteness in the dry type of the processing system. 
Table 1. CBB index and milling difference of clean rice in the dry type of the processing system

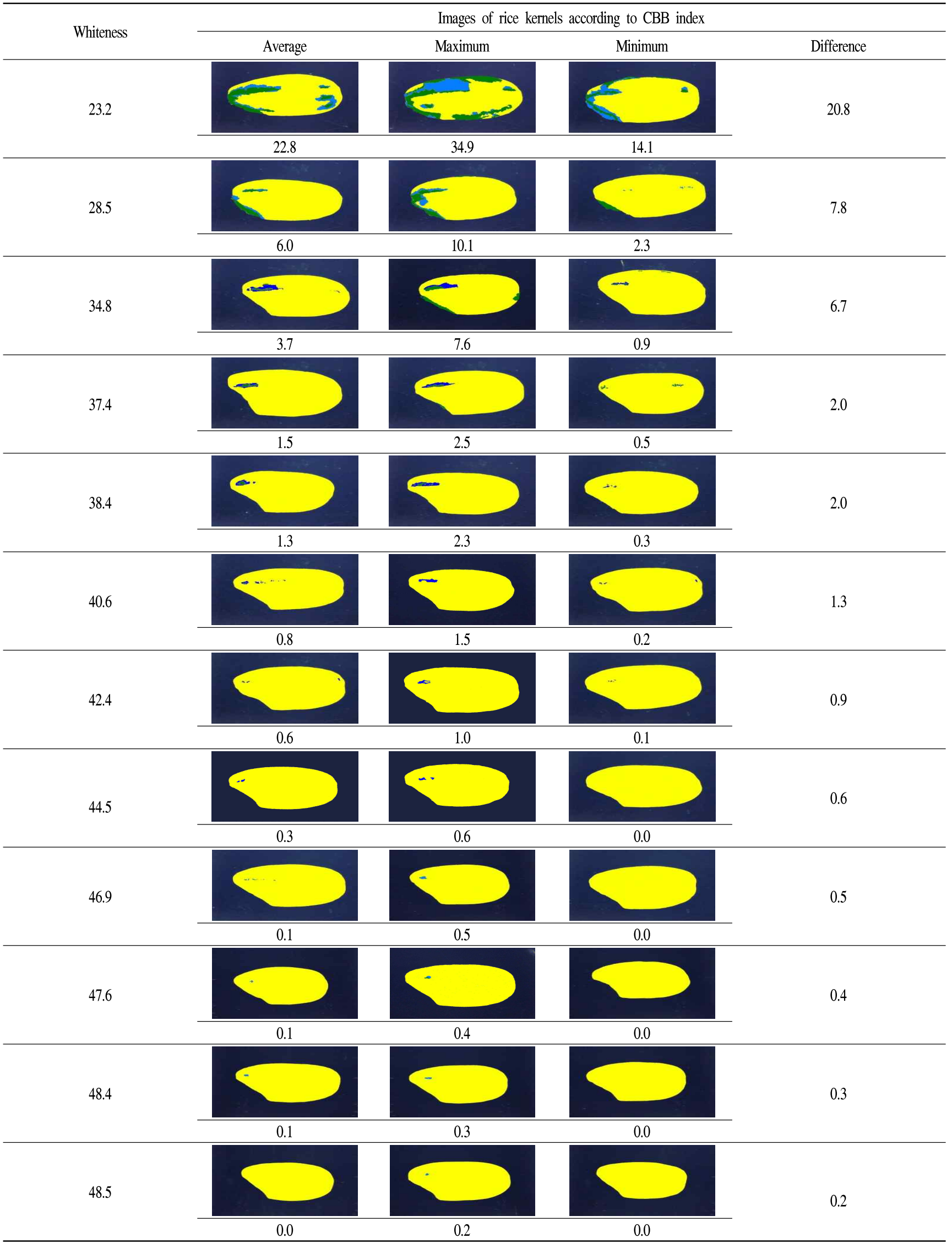


면서 탁도가 감소하였다. 백도 40.6 42.4, 탁도 21.7 15.3 $\mathrm{NTU}$ 사이에서 호분층이 충분하게 제거되었으며, 완전히 제거되어 배유만 남을 경우 전분입자 사이에 작은 공간에 극히 소량의 잔류 미강만이 남아 탁도가 감소하였다. 실험 범위 중 가장 높은 백도 48.5 에서 탁도는 $9.6 \mathrm{NTU}$ 로 최저점 을 나타내었다. 또한, Fig. 2b에서 백도가 증가함에 따라 건고물량은 증가하다가 감소하는 경향을 나타냈다. 백도 34.8 에서 $0.58 \mathrm{~g} / 100 \mathrm{~g}$ 수준으로 최고값을 나타냈고, 백도 48.5 에서 건고물량은 $0.095 \mathrm{~g} / 100 \mathrm{~g}$ 을 나타냈다. 호분층이 완전히 제거된 백도 40.6 42.4 수준에서 도정할 필요가 있 으며, 그 이상의 백도를 위한 도정은 수율을 감소시키므로 품질기준안인 $16.0 \mathrm{NTU}$ 를 만족하기 위한 백도 42.4 수준으 로 도정하여야 한다.

\section{클린라이스 제조조건 별 품질 특성, $\mathrm{CBB}$ index 및 도정 편차, 표면특성}

제조조건 별로 클린라이스의 특성을 비교하기 위해 건 식, 반건식, 가수정미방식에서 백도 $39,40,41,42$ 로 제조하 였다. Fig. 3은 제조방식에 따라 백도 변화에 따른 곡물온도 (a), 함수율(b), 싸라기함량(c)을 나타냈다. 가수정미방식의 경우 건식에서 제조된 클린라이스를 원료로 사용하여 수세 함에 따라 건식 상태의 원료와 동일한 도정도임에도 불구하 고 클린라이스의 백도가 46.4 50.0으로 상승하였는데, 수 세와 건조에 의해서 백화현상이 발생하였기 때문에 백도가 증가하였다(6). 동일한 도정도에서 다른 제조방식과의 비 교를 위해 Fig. 3에서는 가수정미방식의 백도를 원료인 건 태에서의 백도로 나타냈다. Fig. 3a에서 곡물온도는 초기 현미가 $11.1^{\circ} \mathrm{C}$ 이었으며, 건식, 반건식 및 가수정미방식 모 두에서 백도가 높아질수록 곡물 온도가 상승하였지만, 제 조방식에 따라 곡물온도의 상승은 차이를 나타냈다. 백도 42 식 상에서, 건식은 $48.8^{\circ} \mathrm{C}$ 로 상승하였고, 반건식은 $34.9^{\circ} \mathrm{C}$
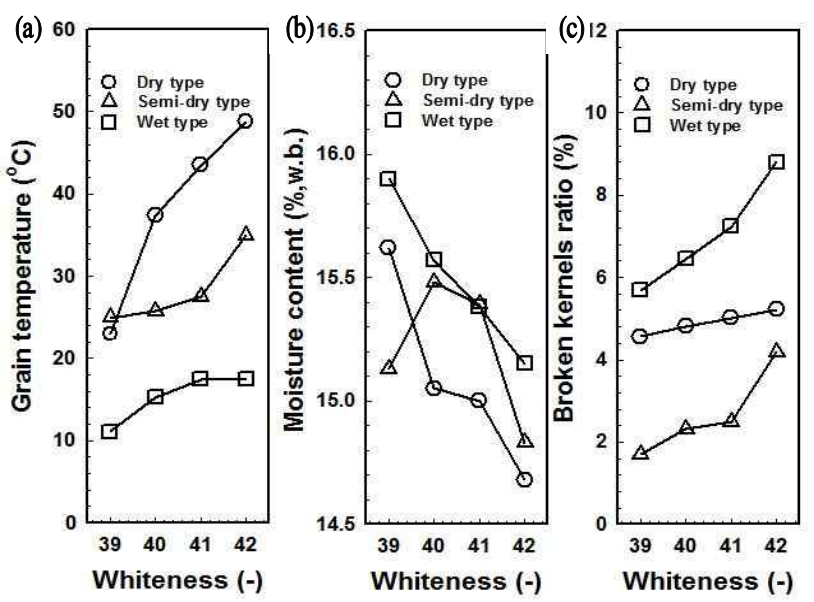

Fig. 3. Variations of grain temperature (a), moisture content (b), and broken kernels ratio (c) with whiteness in the dry, semi-dry, and wet types of the processing system.
로 상승하였으며, 가수정미방식은 원료의 백도 42 에서 17. $6^{\circ} \mathrm{C}$ 로 상승하였다. $\mathrm{Kim}$ 등(17)은 도정시 함수율이 낮으면 정백압력이 증가하고 도정시간이 길어지고, 함수율이 높으 면 표면조직이 연화되어 정백압력이 감소하여 도정시간이 감소한다고 하였다. 정백압력과 도정시간의 증가는 마찰열 을 많이 발생시켜 곡물온도를 상승시키기 때문에, 반건식 에서는 함수율이 건식보다 더 높아 도정시간이 감소하여 곡물온도가 낮게 나타났으며, 가수정미방식은 수세를 거침 에 따라 수세 후 건조과정에도 불구하고 곡물온도가 가장 낮게 나타났다. 또한, Fig. $3 b$ 에서 함수율은 백도가 높아질 수록 감소하였으며, 이는 도정 시 곡물온도 상승에 따라 표면의 수분이 증발하였기 때문이다. 제조방식에 따라서는 사용된 물의 양이 많은 순서대로 가수정미방식 평균 $15.5 \%$, 반건식 평균 $15.2 \%$, 건식 평균 $15.1 \%$ 의 순서로 함수율이 높게 나타났다. Fig. 3c에서 싸라기는 도정이 진행됨에 따라 곡물온도가 상승하고, 내부와 표면의 수분차이로 강도가 저하하여 발생량이 증가한다(18). 도정 후 수세와 건조 과정 을 거치는 가수정미방식이 싸라기 발생량이 가장 높게 나타 났으며, 고습도 상태에서 도정하기 때문에 내부와 표면의 수분차이가 적은 반건식의 싸라기 발생량이 가장 낮게 나타 났다.

클린라이스 제조조건별 표면의 SEM 특성은 Fig. 4 와 같 다. 건식과 반건식 방식은 표면에 굵은 입자형태의 미강이 부착되어 있었는데, 일반 백미에는 표면에 크고 굵은 입자 가 관찰된다는 연구(5)와 동일한 결과를 나타냈다. 한편 백도가 높아질수록 잔류 미강량은 줄어들어 매끄러운 표면 이 나타났다. 가수정미방식으로 제조된 클린라이스의 표면 은 미강이 부착되어 있지 않았으며, 호분층의 벌집구조와, 전분입자의 구조를 뚜렷하게 관찰이 가능하였으며, 무세미 의 표면은 벌집형태의 세포벽 구조를 관찰할 수 있지만, 보통정미에서는 관찰할 수 없다고 보고한 연구결과 $(5,6,19)$ 와 일치하였다. 또한 가수정미방식에서는 건식과 반건식에 서 나타나지 않은 균열을 발견할 수 있었는데, 수세와 건조 과정중에 낟알 내부와 표면의 수분차에 의한 응력이 과다해 서 배유부에 금이 가는 균열이 생긴 것으로 판단되었다(7).

Fig. 5는 클린라이스 제조조건 별 (a) 탁도와 (b) 건고물량 변화를 나타낸다. Fig. 5a에서 건식과 반건식방식은 백도가 증가할수록 탁도는 감소하였으나, 가수정미방식은 이미 수 세가 되어있기 때문에 탁도 변화가 미미하였다. 제조방식 별로는 물을 많이 사용하는 방식일수록 탁도가 낮게 나타났 으며, 특히 가수정미방식이 건식 및 반건식 방식에 비해서 매우 낮은 탁도값을 보였고, 이는 수세과정을 통해 건식 및 반건식보다 부착된 미강량이 적기 때문에 탁도값이 낮게 나타난 것으로 판단되었다(6). Fig. 5b에서 건고물량 또한 백도가 증가함에 따라 감소하였으며, 가수정미방식에서 가 장 낮게 나타났다. 클린라이스 국내 탁도 품질기준안 16.0 $\mathrm{NTU}$ 에 대해, 건식과 반건식에서는 백도 42 에서 만족하였 


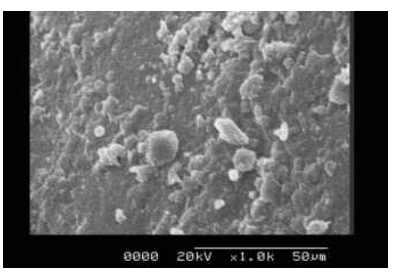

Dry type

Whiteness 39

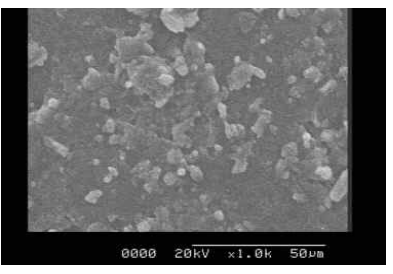

Semi-dry type

Whiteness 39

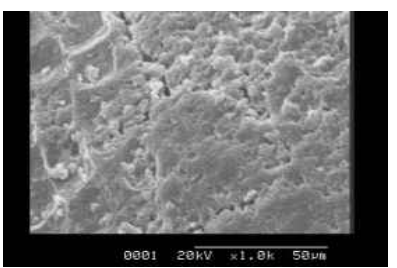

Wet type

Whiteness 39

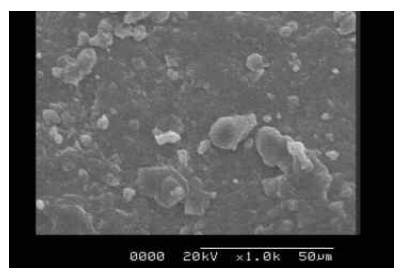

Dry type

Whiteness 40

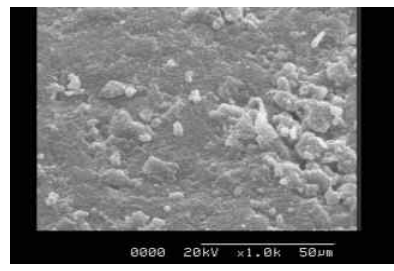

Semi-dry type

Whiteness 40

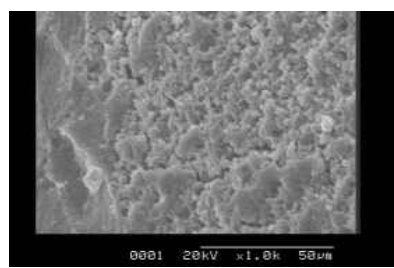

Wet type

Whiteness 40

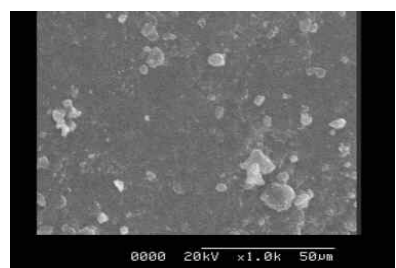

Dry type

Whiteness 41

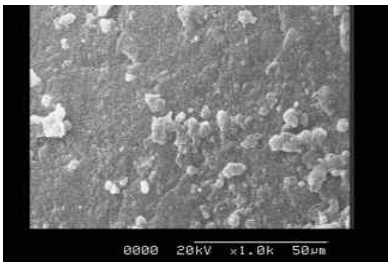

Semi-dry type

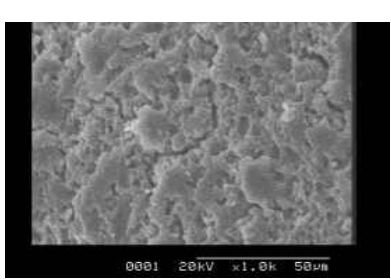

Wet type

Whiteness 41

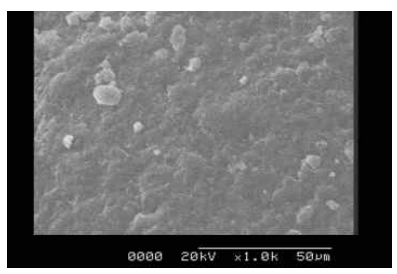

Dry type

Whiteness 42

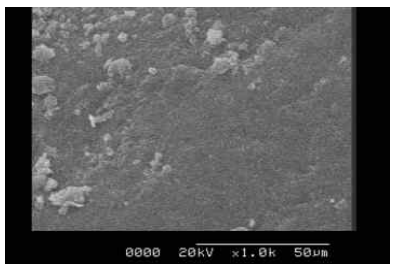

Semi-dry type

Whiteness 42

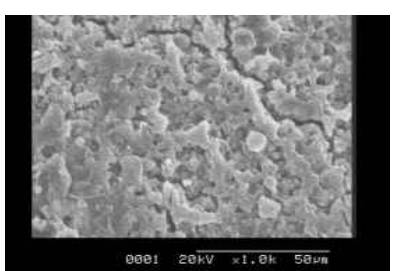

Wet type

Whiteness 42

Fig 4. Surface section by SEM $(\times 1000)$ in the dry, semi-dry, and wet types of the processing system.
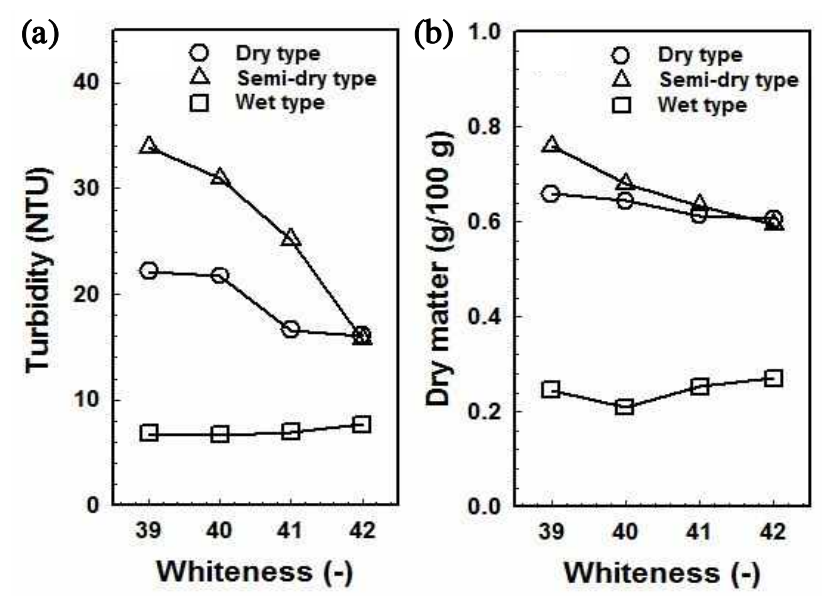

Fig. 5. Variations of turbidity (a) and dry matter (b) with whiteness in the dry, semi-dry, and wet types of the processing system.

으며, 가수정미방식은 모든 백도에서 만족하였다. 가수정 미방식은 낮은 백도에서도 탁도 기준안을 만족하였기 때문 에, 높은 백도로 도정할 필요가 없는 것으로 나타났다.

Fig. 6은 백도변화에 따른 클린라이스 제조조건 별 완전 미수율(a)과 백도 42 의 건식 중량 대비 백도 40,39 의 가수정 미방식의 완전미수율(b)의 비를 나타낸다. Fig. 6(a)에서 완 전미수율은 백도가 증가함에 따라 싸라기 발생율과
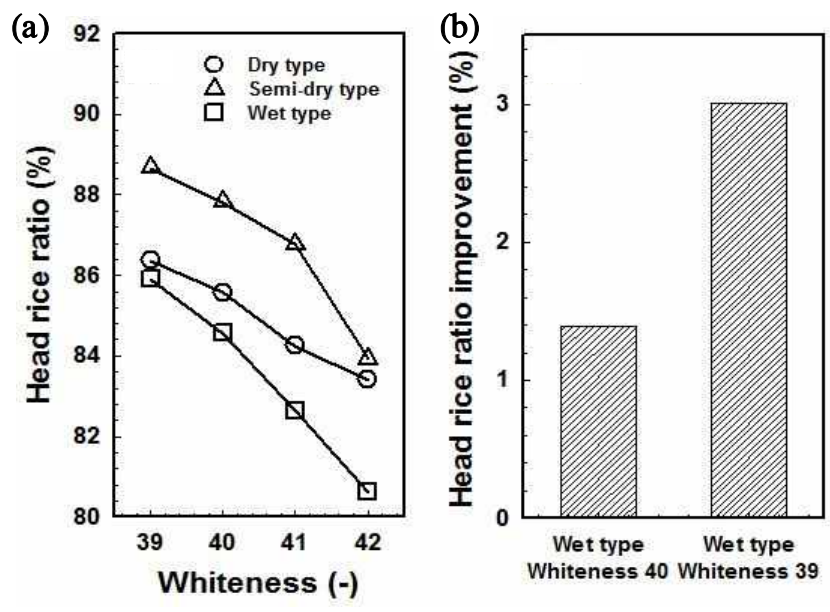

Fig. 6. Head rice ratios (a) in the dry, semi-dry, and wet types of the processing system and head rice ratio improvement (b) in the wet type.

도정도가 증가하여 감소하였다. 싸라기 발생율이 반건식에 서 제일 낮았기 때문에 반건식의 완전미수율이 제일 높게 나타났으며 건식에 비해 평균 $2.2 \%$ 높았고, 가수정미방식 의 완전미수율이 제일 낮게 나타났으며 건식에 비해 평균 $3.9 \%$ 낮았다. 그러나 가수정미방식의 경우 낮은 백도에서 도 기준 탁도 $16.0 \mathrm{NTU}$ 를 만족하기 때문에, 다른 방식이 
백도 42 수준으로 도정되어야 하는 것에 비해 상대적으로 낮은 도정도로 도정이 가능하다. Fig. $6 \mathrm{~b}$ 에서 백도 40 의 가수정미방식과 백도 42 의 건식 방식의 완전미수율을 비교 하였을 때, 가수정미방식의 완전미수율이 건식 방식보다 $1.4 \%$ 높게 나타났다. 또한 백도 39 의 가수정미방식은 백도 42 의 건식보다 $3.0 \%$ 높은 완전미수율을 나타냈다. Kim 등 (8)은 0.01 수준에서 백도 38 수준과 백도 40 수준의 식미품 질이 유의적인 차이를 나타내지 않았다고 하였으며, $\mathrm{Kim}$ 등(12)은 가수정미방식은 함수율이 높게 나타나 지방산가 가 증가하여 저장성이 떨어진다고 하였기 때문에, 식미품 질이 큰 차이가 없어도 되며 빠른 소비가 가능한 경우에 대해서는 가수정미방식으로 도정하는 것이 높은 수율을 얻을 수 있다. 또한, 높은 저장성이 요구될 경우, 반건식 방식이 건식에 비해 평균 $2.2 \%$ 의 높은 완전미수율을 나타 내었기 때문에 반건식 방식이 유리한 것으로 나타났다.

\section{요 약}

클린라이스의 제조방식에 따른 품질 특성을 제시 및 비 교하기 위하여 건식, 반건식, 가수정미방식으로 각각 제조 하여 품질 특성에 대해 연구하였다. 건식 제조방식에서 도 정도를 변화시키며 백도에 따른 $\mathrm{CBB}$ index, 탁도, 건고물량 의 변화를 고찰하였다. 건식 방식에서 백도가 증가할수록 호분층이 완전히 제거되어 $\mathrm{CBB}$ index와 탁도는 감소하였 고 우수한 클린라이스 품질을 나타내었으나, 높은 백도는 과도한 중량 감소로 수율이 낮아지게 되므로 백도 42 이하 로 도정할 필요가 있다. 건식, 반건식, 가수정미방식의 품질 을 비교하기 위해 건식, 반건식에서는 백도 $39,40,41,42$ 수준으로 가공하였고, 가수정미방식은 건식에서 제조된 시 료를 사용하여 수세 및 건조하였으며, 백도에 따른 품질 특성을 측정하였다. 도정이 진행될수록 곡물온도가 상승하 고, 강도가 저하하여 싸라기 발생량이 증가하는데, 도정, 수세와 건조의 여러 과정을 거치는 가수정미방식이 싸라기 발생량이 가장 높게 나타났으며, 반건식이 가장 낮게 나타 났다. 국내 탁도 품질기준안 $16.0 \mathrm{NTU}$ 를 클린라이스의 기 준으로 하였으며, 건식과 반건식에서는 백도 42 에서 만족 하였으며, 가수정미방식에서는 39 42 범위의 모든 백도에 서 만족하였다. 백도 $16.0 \mathrm{NTU}$ 를 만족하는 각 제조방식의 백도에서 완전미수율을 비교하였을 때, 백도 40 의 가수정 미방식에서 완전미수율은 백도 42 의 건식 방식보다 $1.4 \%$ 높게 나타났으며, 백도 39 의 가수정미방식에서 완전미수율 은 백도 42 의 건식 방식보다 $3.0 \%$ 높게 나타났다. 그러나 가수정미방식은 저장성이 떨어지기 때문에 높은 저장성이 요구될 경우 반건식 방식이 유리하며, 백도 39 42에서 건식
보다 평균 $2.2 \%$ 높은 완전미수율을 나타냈다.

\section{감사의 글}

본 연구는 농림축산식품부의 재원으로 농림수산식품기 술기획평가원의 농생명산업기술개발사업의 지원을 받아 연구되었음(과제번호:315036-3)

\section{References}

1. Yamashita R (1993) New technology in grain postharvesting. Farm Machinery Industrial Research Corporation, Tokyo, Japan, p 183-187

2. Katsuragi Y (2003) Prewashed rice: Producing technology and its perspective. J Soc Agri Str, 34, 151-159

3. Ito K (1980) Studies on the characteristics of nonwashrice. J Japanese Soc Agri Machinery, 21, 67-73

4. Jang DI, Han WS, Kim DC, Lee SH (1999) Development of a process for clean-washed rice processing (I). $\mathrm{J}$ of Biosystems Eng, 24, 317-324

5. Choi HS, Cho KH, Park HM, Keum DH (2004) Development of the processing system from pre-washed rice. Agri \& Biosys Eng, 5, 60-63

6. Yokoe M, Kawamura S, Himoto JI, Itoh K (2005) Quality characteristics and storage properties of rinse-free rice (part 1)-Quality characteristics and storage properties of conventional milled rice and rinse-free rice processed by different methods-. J Japanese Soc Agr Machinery, 67, 113-120

7. Yamaguchi S, Yamazawa S, Wakabayashi K, Shibata $\mathrm{T}$ (1980) Experimental study on the internal stress cracking of rice kernel (part 1). J Japanese Soc Agr Machinery, 42, 91-96

8. Kim OW, Kim H, Kim DC, Kim SS (2005) Determination of whitemess condition for efficient milling in rice processing complex. J of Biosystems Eng, 30, 242-248

9. Chung JH, Choi YS, Kwon HK, (1998) Performance evaluation and improvement of medium and small scale rice polishers (I) - small scale rice polisher-. $\mathrm{J}$ of Biosystems Eng, 23, 245-252

10. Chung JH, Kwon HK (1998) Performance evaluation and improvement of medium and small scale rice polishers (II) - medium scale rice polisher-. J of Biosystems Eng, $23,445-456$

11. Chung JH (1999) Development of large-scale rice 
polisher with double polishing stages. J of Biosystems Eng, 24, 309-316

12. Kim OW, Kim H, Han JW, Lee HJ (2014) Storage characteristics of milled rice according to milling system types. Korean J Food Preservation, 21, 308-314

13. Ban T, Susawa K (1974) 1. Studies on grain moisture content measurements by air oven methods (II). J Japanese Soc Agr Machinery, 35, 406-415

14. Yoon DH, Kim OW, Kim H (2006) Modeling of milling degree for milled rice using NMG dying and image processing. J of Biosystems Eng, 31, 524-528

15. Rice fair trade promotion council (2003) Quality labeling guide of rice, Tokyo, Japan, p 1-5
16. Kim OW (2010) Development of the quality standard and related system for clean rice. Final Report of MAFRA, Ministry of Agriculture, Food and Rural Affairs 107015-3

17. Kim OW, Kim H, Lee HJ (2014) Impact of moisture content on milling characteristics of short-grain rice. Appl Eng Agr, 30, 927-933

18. Kim CJ, Lee HJ, Kim OW, Keum DH, Kim H (2007) Effects of abnormal kernels in brown rice on milling characteristics. J of Biosystems Eng, 32, 1-5

19. Matsuda T (2001) Surface structure of conventional milled rice, polished rice and rinse-free rice. J Jpn Rice Millers Assoc, 191, 10-16 